\title{
Validation of learning style measures: implications for medical education practice
}

\author{
Dane M Chapman $^{1,2}$ \& Judith G Calhoun ${ }^{2,3}$
}

BACKGROUND It is unclear which learners would most benefit from the more individualised, studentstructured, interactive approaches characteristic of problem-based and computer-assisted learning. The validity of learning style measures is uncertain, and there is no unifying learning style construct identified to predict such learners.

OBJECTIVE This study was conducted to validate learning style constructs and to identify the learners most likely to benefit from problem-based and computer-assisted curricula.

METHODS Using a cross-sectional design, 3 established learning style inventories were administered to 97 post-Year 2 medical students. Cognitive personality was measured by the Group Embedded Figures Test, information processing by the Learning Styles Inventory, and instructional preference by the Learning Preference Inventory. The 11 subscales from the 3 inventories were factor-analysed to identify common learning constructs and to verify construct validity. Concurrent validity was determined by intercorrelations of the 11 subscales.

RESULTS A total of 94 pre-clinical medical students completed all 3 inventories. Five meaningful learning style constructs were derived from the 11 subscales: student- versus teacher-structured learning; concrete versus abstract learning; passive versus active learning; individual versus group learning, and field-dependence versus field-inde-

${ }^{1}$ University of Colorado School of Medicine, Denver, Colorado, USA

${ }^{2}$ University of Michigan School of Medicine, Ann Arbor, Michigan,

USA

${ }^{3}$ University of Michigan School of Public Health, Ann Arbor, Michigan, USA

Correspondence: Dane M Chapman MD, Division of Emergency

Medicine, University of Colorado Health Sciences Center, 4200 East

Ninth Avenue, B215, Denver, Colorado 80262, USA.

Tel: 001720284 2313; Fax: 001435462 2609;

E-mail: dane.chapman@uchsc.edu pendence. The concurrent validity of 10 of 11 subscales was supported by correlation analysis. Medical students most likely to thrive in a problembased or computer-assisted learning environment would be expected to score highly on abstract, active and individual learning constructs and would be more field-independent.

CONCLUSIONS Learning style measures were validated in a medical student population and learning constructs were established for identifying learners who would most likely benefit from a problem-based or computer-assisted curriculum.

KEYWORDS humans; *education, medical, undergraduate; *learning; *problem-based learning; *computer-assisted instruction; curriculum; cross-sectional studies; cognition; personality; students/ medical/*psychology.

Medical Education 2006; 40: 576-583

doi:10.1111/j.1365-2929.2006.02476.x

\section{INTRODUCTION}

Medical students and residents must learn to rapidly retrieve medical information. Didactics using the lecture format promote the learning of isolated facts, making subsequent rapid retrieval during clinical practice difficult. ${ }^{1,2}$ Problem-based learning (PBL) and computer-assisted learning (CAL) facilitate clinical reasoning processes, including the rapid retrieval of information, and are being used increasingly in medical schools and residency training. ${ }^{3-5}$ It is unclear which learners would be most likely to benefit from the more individualised, student-structured, interactive approach characteristic of these curricula. This study identifies common learning constructs among multiple learning style inventories that would identify such learners. 


\section{Overview}

What is already known on this subject

Problem-based learning (PBL) and computerassisted learning (CAL) are popular in medical schools. Learning style measures are needed to identify the learners most likely to benefit from these curricula. The validity of learning style measures is uncertain.

\section{What this study adds}

Learning style measures were validated in a medical student population. Learning style constructs identified the learners most likely to benefit from PBL or CAL. These PBL and CAL students were significantly more abstract, active, individual and field-independent.

\section{Suggestions for further research}

Further research might determine tolerance for unmatched instruction methods and learning style, and might replicate this study in other medical student populations.

Due to the overlap of terminology and to the uncertainty regarding the behavioural constructs underlying learning styles, Curry ${ }^{6}$ proposed a unifying 3-level hypothesis. The inner or core level was labelled 'cognitive personality' and refers to an individual's more permanent or stable learning personality. Existing instruments thought to measure this level include those of Witkin, ${ }^{7}$ Myers-Briggs ${ }^{8}$ and Kagan. ${ }^{9}$ The middle level was described as 'information processing' and relates to an individual's approach to assimilating information through orienting, sensory loading, short-term memory, enhanced associating, coding and longterm storage. Because information processing was considered to be influenced by environmental variables, it was described as a less stable construct than cognitive personality. Existing measures of information processing include those of Kolb, ${ }^{10}$ Tamir et al.,${ }^{11}$ Schmeck et al., ${ }^{12}$ and Honey and Mumford. ${ }^{13}$ The outer or skin level was described as instructional preference' as it relates to how individuals prefer to learn, whether through lectures, individual study or small-group study. As the outermost stratum, instructional preference was thought to be the least stable and most easily influenced behavioural construct. Three existing instructional preference instruments were recommended. ${ }^{14-16}$

To date there has been no empirical testing to determine the construct or concurrent validity of the 3 proposed levels of cognitive personality, information processing and instructional preference in preclinical medical students. By better understanding learning style constructs, we might be able to determine the relative effect of each construct upon medical student performance, certification examinations, attitude, specialty choice, residency training success and continuing medical education. ${ }^{17,18}$

'Construct validity' refers to whether a scale measures the unobservable construct that it was designed to measure. For example, if an analysis of learning style constructs identified the 3 component layers as described by Curry, ${ }^{6}$ then construct validity would be established for the 3-layer hypothesis. When we claim construct validity, we claim that our observed pattern - how things operate in reality - corresponds with our theoretical pattern - how we think the world works. ${ }^{19}$ 'Concurrent validity' is a form of construct validity where the measures being validated are correlated with a criterion measure known to be valid. A valid test or scale measures what it purports to measure. Concurrent validity cannot exceed the square of the correlation between the 2 measures (i.e. the measure being validated and the criterion measure).${ }^{19}$ The criterion measure is the standard by which a measure is evaluated.

The objectives of this study were to:

1 determine the construct validity of the 3-level learning style hypothesis (i.e. whether the 3 measures representing different learning style levels behave differently, as expected);

2 estimate the concurrent validity of the subscales of the 3 learning style inventories (i.e. whether a high correlation exists among subscales measuring the same behavioural constructs), and

3 identify the most likely subgroup of medical students to benefit from PBL and CAL.

\section{METHODS}

\section{Study design and participants}

Using a cross-sectional, survey design, 97 of 191 preclinical medical students participated in the study 
prior to a computer-based simulation elective designed to teach and evaluate medical problemsolving skills.

\section{Description of cognitive style inventories}

Of the multiple cognitive style inventories available, the following inventories were found to have the best documented psychometric profiles to represent the 3 levels of learning style proposed by Curry. ${ }^{6}$

1 Cognitive personality, an individual's more permanent or stable learning style, was measured by the Group Embedded Figures Test (GEFT) (Consulting Psychologists Press, Inc., Palo Alto, California, USA). The GEFT classifies learners as either field-dependent or field-independent and demonstrates 'absolute stability' even over extended periods. ${ }^{7}$

2 Information processing, the second, less permanent level of learning style, is influenced by environmental variables and relates to an individual's approach to assimilating information through orienting, sensory loading, short-term memory, enhanced associating, coding and longterm storage. ${ }^{6}$ It was measured by the Kolb Learning Styles Inventory (LSI). ${ }^{10}$ The LSI classifies the participant's learning style preference as concrete experience, reflective observation, abstract conceptualisation or active experimentation.

3 Instructional preference, the third level of learning style, relates to how individuals prefer to learn, whether through lectures, individual study or small-group study. It is thought to be the most easily influenced behavioural construct ${ }^{6}$ and was measured by Rezler and Rezmovic's Learning Preference Inventory (LPI). ${ }^{14}$ The LPI classifies participants' learning preferences as abstract, concrete, teacher-structured, student-structured, interpersonal (group) or individual.

\section{Administration, scoring and analyses}

All instruments were administered and scored as recommended in their respective documentation. Group comparisons were made using ANOvA statistics. The 11 subscale scores were factor-analysed with factor rotations according to the varimax criteria. This was done to identify common learning constructs among the 3 representative learning style inventories and to test the 3-level learning style hypothesis. If the 3 learning style inventories measure different behavioural constructs, then 3 separate factors should emerge during factor analysis to support the construct validity of the 3-level learning style hypothesis. Subscale scores were correlated using the Pearson product-moment technique as a measure of concurrent validity of common subscales among the 3 inventories. High concurrent validity would be supported if there was a high correlation between subscales measuring the same behavioural construct.

\section{RESULTS}

The 97 medical students participating in the study did not differ significantly from the remainder of the medical school class $(n=94)$ in ethnicity, sex, prior clinical experience on hospital wards, or on clinical reasoning assessments. The mean subscale scores \pm SD for both male and female medical students and total scores \pm SD are reported in Table 1 . No significant gender differences were found for any of the learning style subscales. Mean scores for medical students were in the ranges previously reported for college students. ${ }^{7,10,14}$

Table 2 displays the results of the simultaneous factor analysis of the 11 learning style subscales. Subscales from the LSI and the LPI tended to group together into 4 meaningful learning style constructs, while the GEFT loaded primarily onto a fifth construct. Interestingly, all 5 of the newly derived learning style constructs represented meaningful 'bipolar factors', where at least 1 of the 11 subscales loaded positively and another of the subscales loaded negatively on each of the 5 factors (Table 2).

The 5 newly derived learning style constructs are:

1 student-versus teacher-structured learning (18.8\% of the total variance of scores), which reflects a learning preference for student-organised autonomy and self-direction rather than a well organised, teacher-directed class;

2 concrete versus abstract learning ( $13.8 \%$ of the total variance of scores), which represents a learning preference for active, experience-based learning rather than the more analytical, conceptual approach that emphasises the learning of theories and general principles;

3 passive versus active learning $(11.0 \%$ of the variance), which reflects a learning preference for passive lectures rather than active experimentation such as PBL;

4 individual versus group learning (9.9\% of the score variance), which reflects a preference for learning alone on tasks that are solitary rather than working with others, and 
Table 1 Subscale scores (mean \pm SD) of the Group Embedded Figures Test (GEFT), Learning Styles Inventory (LSI) and Learning Preference Inventory (LPI) in preclinical medical students* $(n=94)$

\section{GEFT $\dagger$}

Field-dependence/

field-independence

LSI subscale

Concrete experience

Reflective observation

Abstract

Conceptualise

Active experimentation

LPI subscale§

Abstract

Concrete

Teacher-structured

Student-structured

Interpersonal

Individual
Male
$(n=71)$

$(n=71)$

$14.9 \pm 3.3$

Male

$(n=71)$

$13.8 \pm 3.0$

$13.5 \pm 3.1$

$18.5 \pm 3.6$

$16.0 \pm 3.2$

Male

$(n=70)$

$48.9 \pm 12.9$

$64.1 \pm 10.2$

$54.7 \pm 14.0$

$50.2 \pm 10.2$

$42.0 \pm 12.9$

$54.9 \pm 10.5$
Female

$(n=24)$

$15.2 \pm 2.5$

Female

$(n=24)$

$15.0 \pm 3.3$

$13.3 \pm 2.9$

$18.9 \pm 2.4$

$15.2 \pm 3.7$

Female

( $n=24)$

$48.8 \pm 10.8$

$61.0 \pm 12.7$

$49.9 \pm 16.6$

$54.9 \pm 12.8$

$45.7 \pm 4.6$

$53.7 \pm 1.5$
Total

$(n=95)$

$15.0 \pm 3.1$

Total

$(n=95)$

$14.2 \pm 3.1$

$13.4 \pm 3.1$

$18.6 \pm 3.4$

$15.8 \pm 3.3$

Total

$(n=94)$

$48.9 \pm 12.3$

$63.3 \pm 10.9$

$53.5 \pm 14.7$

$51.4 \pm 11.1$

$43.0 \pm 13.4$

$54.6 \pm 10.7$

* No significant gender differences on any scale using Anova, $P>0.050$.

$\dagger$ Established college student norms: field-dependent $(0-10)$, field-independent (11-18). ${ }^{7}$

+ All scores within the 40th to 60th percentiles of established norms for college students. ${ }^{10}$

$\S$ Possible range is $15-90$ with a low score meaning a low preference and a high score a higher preference. ${ }^{14}$

Table 2 Varimax factor matrix for subscales of the Group Embedded Figures Test (GEFT), Learning Styles Inventory (LSI) and Learning Preference Inventory (LPI) in post-Year 2 medical students $(n=94)$

Rotated factors*

\begin{tabular}{lr} 
Subscale & \multicolumn{1}{l}{} \\
& \\
LPI.TS & -0.86 \\
LPI.SS & 0.76 \\
LPI.CO & -0.40
\end{tabular}

LSI.CE

LPI.AB

LSI.AC

LSI.RO

LSI.AE

LPI.IN

LPI.IP

GEFT

Eigenvalue $\ddagger \quad 2.06$

$\%$ variance
2

0.76

$-0.40$

18.8
-0.69
0.59
0.55

0.80

$-0.75$

$-0.82$

0.67

1.09

9.9
5

$\mathbf{h}^{2} \dagger$

0.82

0.72

0.30

0.67

0.57

0.34

0.73

0.67

0.84

0.60

0.43

Correlations accounting for $<15 \%$ of the variance $(r<0.388)$ have been omitted.

$\mathrm{TS}=$ teacher-structured; $\mathrm{SS}=$ student-structured $; \mathrm{CO}=$ concrete $; \mathrm{CE}=$ concrete experience; $\mathrm{AB}=$ abstract; $\mathrm{AC}=$ abstract conceptualisation;

$\mathrm{RO}=$ reflective observation; $\mathrm{AE}=$ active experimentation; $\mathrm{IN}=$ individual; $\mathrm{IP}=$ interpersonal.

* Rotated principal components (varimax criteria). Factor V was accepted although its eigenvalue was $<1$ as it primarily represents the loading of the Group Embedded Figures Test (GEFT).

$\dagger$ Estimated communality or the percent of total variable variance explained by the 5 -factor solution.

\$ Eigenvalue $=$ total variance in data accounted for by factor.

$\S$ Percent of total variance accounted for by factor.

5 field-dependence versus field-independence ( $7.5 \%$ of the variance), which represents a learning or personality tendency to be socially influenced and affected by surroundings rather than being internally grounded and analytical, and less influenced by others or surroundings. 
Factor 5 (field-dependence versus field-independence) was accepted into the model although it had an eigenvalue $<1.0$, as it primarily represented the GEFT.

The field-dependence/independence construct differed from learning preference and instructional preference constructs as it loaded onto its own factor supporting a stable, cognitive personality learning style level. A second learning style level is suggested to account for learning and instructional preference measures, supporting a 2-level rather than a 3-level learning style hypothesis. Learning/instructional preference constructs explain the most variance in learning style factor analysis, accounting for $87.7 \%$ of the total variance explained by the 5 -factor model.

Although the construct validity of the 3-level learning style hypothesis was only partially confirmed, the construct and concurrent validities were supported for the learning style behavioural constructs. The construct validity of all subscales was supported except for the LPI concrete subscale. This subscale did not correlate with the concrete versus abstract learning construct.

The correlation results supported the concurrent validity of 10 of 11 subscales. Inspection of Table 3 reveals several significant correlations $(P<0.05)$, as described below.

1 High negative correlations were identified between subscales measuring bipolar constructs: LPI-teacher-structured versus LPI-student-structured learning $(r=-0.62)$; LSI-concrete experi- ence versus LSI-abstract conceptualisation learning $(r=-0.43)$; LSI-reflective observation versus LSI-active experimentation $(r=-0.53)$, and LPI-individual versus LPI-interpersonal (group) learning $(r=-0.51)$.

2 Moderate positive correlations existed between the 2 subscales measuring abstract learning, the LSI-Abstract conceptualisation and the LPIAbstract scales $(r=0.296)$.

3 Only the LPI-Concrete subscale did not correlate with other subscales measuring concrete versus abstract learning preferences $(P>0.05)$. Accordingly, the LPI-Concrete subscale was dropped from further subscale analyses of the concrete versus abstract dimension.

The correlation analyses also provided insight into relationships among the 5 newly defined, learning style constructs (Table 3 ), as follows:

1 student-structured medical students were more individual learners, while teacher-structured students were neither predominately individual nor group learners;

2 student-structured students were neither more concrete nor abstract in their learning style; in contrast, teacher-structured students tended to be more concrete and less abstract, and

3 no clear correlations were found among the teacher- versus student-structured learning construct and either the active versus passive learning style dimension or the field-dependent versus field-independent dimension.

Finally, when mean subscale scores were compared for subscales loading onto the new bipolar factors

Table 3 Pearson product-moment correlations* of the Group Embedded Figures Test (GEFT), Learning Styles Inventory (LSI) and Learning Preference Inventory (LPI) in pre-clinical medical students $(n=94)$

\begin{tabular}{|c|c|c|c|c|c|c|c|c|c|c|c|}
\hline & GEFT & $\mathbf{C E}$ & RO & $\mathbf{A C}$ & $\mathbf{A E}$ & AB & CO & TS & SS & IP & IN \\
\hline GEFT & 1.0 & 0.127 & -0.180 & 0.098 & -0.211 & 0.249 & -0.068 & 0.026 & -0.086 & -0.090 & -0.073 \\
\hline LSI.CE & & 1.0 & 0.048 & -0.432 & -0.243 & -0.183 & -0.074 & 0.140 & -0.002 & 0.257 & -0.207 \\
\hline LSI.RO & & & 1.0 & -0.278 & -0.531 & -0.107 & -0.122 & 0.077 & -0.153 & 0.256 & 0.011 \\
\hline LSI.AC & & & & 1.0 & -0.088 & 0.296 & -0.118 & 0.008 & -0.62 & -0.200 & 0.066 \\
\hline LSI.AE & & & & & 1.0 & -0.105 & 0.218 & -0.034 & 0.088 & -0.070 & -0.064 \\
\hline LPI.AB & & & & & & 1.0 & -0.170 & -0.419 & -0.070 & -0.212 & -0.048 \\
\hline LPI.CO & & & & & & & 1.0 & 0.165 & -0.371 & -0.158 & -0.434 \\
\hline LPI.TS & & & & & & & & 1.0 & -0.616 & -0.133 & -0.218 \\
\hline LPI.SS & & & & & & & & & 1.0 & -0.151 & 0.41 \\
\hline LPI.IP & & & & & & & & & & 1.0 & -0.511 \\
\hline LPI.IN & & & & & & & & & & & 1.0 \\
\hline
\end{tabular}


(see means for 'Total score', Table 1), medical students were found to be significantly more:

1 abstract than concrete learners, preferring an analytical, conceptual approach with a preference for learning theories and general principles $\left(F_{1,188}=86.92, P=0.000\right)$;

2 active than passive learners, preferring an active, 'doing' learning mode, with a dislike for lectures $\left(F_{1,188}=26.7, P=0.000\right)$;

3 individual than group learners, preferring to work alone on tasks that are solitary rather than working with others $\left(F_{1,186}=43.0, P=0.000\right)$, and 4 field-independent than field-dependent, suggesting an analytical rather than a global approach to learning.

Mean medical student scores on the student- versus teacher-structured bipolar factor were not significant, indicating that there was no predominant overall preference for either student-structured or teacherstructured learning among medical students.

\section{DISCUSSION}

These results provide much needed insight into learning style theory. They also suggest common elements among existing learning style inventories. Five underlying learning style constructs were measured by the 3 inventories tested. These can be categorised into 2 underlying learning style levels:

1 cognitive personality, and

2 learning/instructional preference.

The 4 learning/instructional preference constructs explain the most variance in learning style factor analysis: student- versus teacher-structured learning was the most significant learning style construct, accounting for nearly $20 \%$ of the variance. Construct and concurrent validities were supported for the 5 learning style constructs.

Based upon these newly described learning style constructs, those medical students most likely to do well in a PBL or CAL environment would tend to score highly on abstract, active and individual learning and would be more field-independent. While the student-structured versus teacher-structured learning style construct accounted for the most variance in factor analysis, medical students did not show a strong preference as a group for either student- or teacher-structured learning. Other researchers have found that mature students were more likely to prefer student-structured learning, and that preference for concrete learning may increase as a function of course instruction. ${ }^{20}$ Medical students in this study tended to be more abstract and less concrete, preferring to focus on theories and general principles rather than on learning tangible, specific tasks or facts. It may be that, given the massive bombardment of information they experience during medical school, medical students are saturated with facts and would prefer to focus on the underlying theories or principles that might actually prove more useful to them throughout their medical careers.

While providing needed insight, the study has certain limitations. First, only 1 inventory was tested for each of the 3 levels of learning style outlined by Curry. ${ }^{6}$ Selection of the inventory to represent each learning style level was based on the degree of supporting psychometric documentation and on the likelihood of individual versus group study preferences among medical students. It is possible that, had other learning style inventories been tested, additional learning style constructs would have been identified. Secondly, the 97 medical students who participated in the study were not a random sample of the 191 students in the medical school class, but were participants on a computer-based medical problemsolving elective. The results may have been biased in favour of medical students who preferred small-group or student-structured learning activities. However, this bias would be expected to be minimal as no significant differences were found between study participants and the remainder of the class on ethnicity, sex, prior clinical experience on hospital wards, or on other cognitive PBL assessments used to evaluate all students. Finally, the order of learning style inventory administration was not controlled due to the logistical demands of the study. Students completed the LPI and LSI at their leisure a few days prior to the GEFT, which was administered during the introduction to the computer simulation elective. However, there was no reason to suggest an order effect and it was considered more important to administer all 3 inventories prior to the computer simulation experience.

Although medical students may score in a particular manner along several learning style constructs, further longitudinal research is needed to determine whether learners can increase their range of tolerance for certain learning styles that they may initially prefer less (thus resolving the mismatch between learning style and instructional method). There is some research to suggest that learning maturation results from a mismatch between learning style and 
instructional method if the mismatch is gradually introduced and mentored. ${ }^{21,22}$ However, other research strongly supports increased learning efficiency resulting from matching learning styles and instructional methods. ${ }^{23}$ Finally, confirmatory factory analysis of the 5 empirical learning style constructs would be beneficial using additional medical student populations and perhaps other learning style inventories. As these 5 learning style constructs are shown to be consistently valid, then more accurate determinations could be made of their relative impact upon medical student clinical performance, attitude, specialty choice, residency training success and even, perhaps, mode of continuing medical education.

The learning style of medical students has relevance for medical educators, medical administrators and medical students themselves. By adapting learning tasks and teaching methods to students' learning styles and preferences, medical student learning and attitudes improve. ${ }^{24}$ Many medical students are frustrated under a traditional medical school curriculum and few experience the satisfaction of realising their full potential. Good course design must be flexible enough to meet each student's preferred learning style. For example, CAL can be adjusted to the varying styles of different learners, thus helping them to overcome their learning weaknesses. Designing courses that take student learning styles into account improves student responses to the material and helps students become better learners. ${ }^{24}$ Perhaps greater concordance among medical education practice and student learning styles would restore an infectious enthusiasm for learning in our schools of medicine.

\section{CONCLUSIONS}

Medical students who elected a medical problemsolving computer simulation course demonstrated learning styles that were more likely to be fieldindependent, active and abstract, with less preference for learning with others in groups. Three learning style inventories, the Group Embedded Figures Test, the Learning Styles Inventory and the Learning Preference Inventory were validated in a medical student population. Each inventory contributed to at least 1 of 5 unique learning style constructs, although significant overlap was found between the Learning Style and Learning Preference Inventories. Learning style constructs were established for identifying learners who would be most likely to benefit from a problem-based or computerassisted curriculum.
Contributors: DMC contributed to the study conception and design, data analysis and interpretation, and to drafting and revising the article. JGC contributed to the study conception and design and to critical appraisal of the article. Acknowledgements: we are indebted to Robert Bartlett MD and Richard Judge MD, course directors of the problem-based learning curriculum, for their enthusiastic endorsement of the medical problem-solving computer simulation elective; the 97 University of Michigan medical students who enrolled in the elective; the Taubman Medical Library Learning Resource Center staff for their essential role in making the computer simulation elective an overwhelming success; Wayne K Davis PhD, Fredric Wolf PhD, Elaine Hockman PhD, Nancy Allen PhD, Adrian VanMondfrans PhD, Victor Bunderson PhD, Russell Osguthorpe PhD, and Sally Cavanaugh PhD for their insightful review of and recommendations for this work, and to Becky Bluett and Christine Downs for their assistance in preparing the manuscript.

Funding: University of Michigan Curriculum Innovation Project.

Conflicts of interest: none.

Ethical approval: authors state that ethical approval was not required.

\section{REFERENCES}

1 Curry L, Wergin JF. Educating Professionals: Responding to New Expectations for Competency and Accountability. San Francisco: Jossey-Bass 1993;xi-xii.

2 Chapman DM. Making medical school fun while keeping pace with science and technology. Pharos Alpha Omega Alpha 1984;47(1):29-34.

3 Van Gessel E, Nendaz MR, Vermeulen B, Junod A, Vu NV. Development of clinical reasoning from the basic sciences to the clerkships: a longitudinal assessment of medical students' needs and self-perception after a transitional learning unit. Med Educ 2003;37:966-74.

4 Friedman CP. The marvellous medical education machine or how medical education can be unstuck in time. Acad Med 2000;75 (10 (Suppl):137-42.

5 Hawkins R, Gaglione MM, LaDuca T, Leung C, Sample L, Gliva-McConvey G, Liston W, De Champlain A, Ciccone A. Assessment of patient management skills and clinical skills of practising doctors using computerbased case simulations and standardised patients. Med Educ 2004;38:958-68.

6 Curry L. An organisation of learning style theory and constructs. In: Curry L, ed. Learning Style in Continuing Medical Education. Ottawa: Canadian Medical Association 1983;115-31.

7 Witkin HA. Stability of cognitive style from childhood to young adulthood. J Personality Soc Psychol 1967;7:291300.

8 McCaulley MH. Application of the Myers-Briggs Type Indicator to Medicine and Other Health Professions. Monograph 1, Contract no. 23-76-1978, 0051. 
Washington, DC: Health Resources Administration, US Department of Health, Education and Welfare 1978.

9 Kagen J. Impulsive and reflective children: significance of conceptual tempo. In: Krumboltz JD, ed. Learning and the Educational Process. Chicago: Rand McNally 1965;131-61.

10 Kolb DA. Learning Styles Inventory. In: Kolb DA, Rubin IM, McIntyre JM, eds. Organizational Psychology, an Experimental Approach. Englewood Cliffs, New Jersey: Prentice Hall, Inc. 1971.

11 Tamir P, Schiffman A, Elstein AS, Molidor JB, Krupka JW. Development and exploratory trials of a cognitive preference inventory for medical students. Med Educ 1979;13:401-5.

12 Schmeck RR, Ribich F, Ramanaiah N. Development of a self-report inventory for assessing individual differences in learning processes. Appl Psychol Meas 1977;1:413-31.

13 Cockerton T, Naz R, Sheppard S. Factorial validity and internal reliability of Honey and Mumford's Learning Styles Questionnaire. Psychol Rep 2002;91 (2):503-19.

14 Rezler AG, Rezmovic V. The Learning Preference Inventory. J Allied Health 1981;10:28-34.

15 Friedman CP, Stritter FT. An empirical inventory comparing instructional preferences of medical and other professional students. Proceedings of the 15th Annual Conference on Research in Medical Education, San Francisco 1976;63-8.

16 Riechmann SW, Grasha AF. A rational approach to developing and assessing the construct validity of a student learning style scales instrument. J Psych 1974;87:213-23.

17 Curry L. Cognitive and learning styles in medical education. Acad Med 1999;74(4):409-13.

18 Lynch TG, Woelfl NN, Steele DJ, Hanssen CS. Learning style influences student examination performance. Am J Surg 1998;176:62-6.

19 Trochim WM. The Research Methods Knowledge Base. 2nd edn. http://trochim.human.cornell.edu/kb/ indx/htm. [Accessed 10 January 2005.]

20 Clare K, Van Deursen R. The fight against professional obsolescence should begin in the undergraduate curriculum. Med Teacher 2000;22(2):160-3.

21 Clare K, Van Deursen R. Student learning preferences reflect change. Med Teacher 2002;24(1):32-40.

22 Healey M, Jenkins A. Learning Cycles and Learning Styles. Kolb's Experiential Learning Theory and its Application in Geography in Higher Education. http://www2.glos.ac.uk/gdn/discuss/kolb1.htm. [Accessed 13 January 2005.]

23 Robotham D. The Application of Learning Style Theory in Higher Education Teaching. http://www2. glos.ac.uk/gdn/discuss/kolb2.htm. [Accessed 10 January 2005.]

24 Henke H. Learning Theory: Applying Kolb's Learning Style Inventory with Computer-based Training. http:// www.chartula.com/LEARNINGTHEORY.PDF. 9-10. [Accessed 10 January 2005.]

Received 20 January 2005; editorial comments to authors 14 April 2005; accepted for publication 19 December 2005 